\title{
Drug transporter and oxidative stress gene expression in human macrophages infected with benznidazole-sensitive and naturally benznidazole-resistant Trypanosoma cruzi parasites treated with benznidazole
}

\author{
Jair Téllez ${ }^{1,2^{*}} \mathbb{0}$, Ibeth Romero ${ }^{1,3}$, Alvaro José Romanha ${ }^{1}$ and Mario Steindel ${ }^{1 *}$
}

\begin{abstract}
Background: Chagas disease is a potentially life-threatening disease caused by the protozoan parasite Trypanosoma cruzi. Current therapeutic management is limited to treatment with nitroheterocyclic drugs, such as nifurtimox (NFX) and benznidazole (BZ). Thus, the identification of affordable and readily available drugs to treat resistant parasites is urgently required worldwide. To analyse the effects of BZ on human macrophage gene expression, a quantitative PCR ( $\mathrm{PPCR}$ ) array analysis was performed using drug transporter and oxidative stress pathway genes to compare the gene expression profiles of human differentiated THP-1 macrophage (THP-1 MФ) cells infected or not with benznidazolesensitive (CL Brener) and naturally benznidazole-resistant (Colombiana) T. cruzi parasites followed by treatment with BZ.

Results: The gene expression analysis indicated that the expression levels of 62 genes were either up- or downregulated at least 3-fold in the host upon infection with CL Brener and BZ treatment, of which 46 were upregulated and 16 were downregulated. Moreover, the expression level of 32 genes was altered in THP-1 M $\Phi$ cells infected with Colombiana and treated with BZ, of which 29 were upregulated and 3 were downregulated. Our results revealed that depending on the specific condition, human THP-1 MФ cells infected with T. cruzi strains with sensitive or resistant phenotypes and treated with BZ expressed high mRNA levels of AQP1, AQP9 and ABCB1 (MDR1) compared to those of the control cells.

Conclusions: Our findings suggest that the proteins encoded by AQP1, AQP9 and ABCB1 may be implicated in benznidazole detoxification. Therefore, studies on gene expression are required to better understand the host response to pathogens and drug treatment integrated with functional and metabolic data to identify potentially novel targets for the treatment of this important and neglected tropical disease.
\end{abstract}

Keywords: Chagas disease, Host-pathogen interactions, Trypanosoma cruzi, Uptake, Benznidazole

*Correspondence: jaircinio@gmail.com; mario.steindel@ufsc.br

${ }^{1}$ Laboratorio de Protozoologia, Departamento de Microbiologia, Imunologia e Parasitologia, Centro de Ciências Biológicas, Universidade Federal de Santa Catarina, Florianópolis, SC, Brazil

Full list of author information is available at the end of the article 


\section{Background}

Chagas disease is a neglected tropical disease that affects millions of people worldwide and represents a major public health problem. Acute infection control strategies depend on chemotherapy. Since the early 1960s, BZ (N-benzyl-2-nitroimidazole acetamide) has been the drug used for Chagas disease treatment, especially in Central and South American countries [1-3]. Therapeutic schemes based on BZ have been widely accepted in the acute phase of infection by Trypanosoma cruzi; however, marked side effects associated with low specificity and systemic toxicity have been reported $[4,5]$.

Nitroheterocyclic compounds, such as nifurtimox (NFX) and BZ, generally act as prodrugs that need to be activated to assert their cytotoxic effects against T. cruzi parasites [6, 7]. BZ activation has been demonstrated to involve type I nitroreductase (NTR) enzymes present in parasites but absent in humans, as well as in the reduction and therefore activation of BZ [8, 9]. Type I NTRs catalyse the reduction of nitroheterocyclic compounds within the parasite and produce a series of metabolites to yield 4,5-dihydroxyimidazole to release glyoxal, promoting damage to macromolecules such as DNA and forming adducts with proteins, DNA and small molecules, as in the case of glutathione [8]. However, in mammalian cells, $\mathrm{BZ}$ is metabolized by the reduction of a nitro group to an amino group by a type II NTR [10]. As a result of the re-oxidation process, enzymatic processing of $\mathrm{BZ}$ leads to the formation of reactive intermediates, such as a nitro anion radical $\left(\mathrm{R}-\mathrm{NO}_{2}{ }^{-}\right)$and the formation of reactive oxygen species (ROS) and reactive nitrogen species (RNS) [6]. This process increases the toxicity of BZ towards both the parasite and the host cells $[11,12]$.

Drug treatment of intracellular infections requires chemotherapeutic agents to enter and interact inside the host cell to exert their effects, reaching an ideal concentration to eliminate the causal agent. Once inside the cell, drugs may be exposed to different biotransformation processes, which determine their efficacy and toxicity [13]. Thus, BZ has been reported to induce changes in the gene activation of drug transporters in host cells, especially $P-g p$ and $M R P 2$. ABC transporters affect the therapeutic efficacy of BZ by increasing the efflux and/ or decreasing the intracellular accumulation of the drug [14].

To provide an initial assessment of potential drug transporters and oxidative stress-related pathways involved in the toxic effects of BZ in host cells, we studied the expression of specific drug transporters and oxidative stress genes in human macrophages infected with T. cruzi strains with different BZ sensitivity phenotypes followed by treatment with BZ.

\section{Methods}

\section{Parasite cultures}

Epimastigotes of the T. cruzi CL Brener clone (sensitive phenotype) and the T. cruzi Colombiana (resistant phenotype) strain, previously characterized by others authors as benznidazole-sensitive or naturally benznidazole-resistant parasites [15-17] were used in the present study. Here, resistance is defined as the ability of the parasite to differentially survive the effects of $\mathrm{BZ}$ exposure in vitro in comparison with the sensitive control. Parasites were maintained in culture using liver infusion tryptose medium (LIT) as previously described [18]. T. cruzi culture-derived trypomastigotes were obtained by in vitro infection of THP-1 macrophage-like cells (ATCC) using previously described conditions [18]. Briefly, differentiated THP-1 macrophages were infected with $T$. cruzi trypomastigotes at a parasite to cell ratio of $3: 1$, and infection was allowed to proceed for $2 \mathrm{~h}$ in FBSRPMI medium at $37{ }^{\circ} \mathrm{C}$ and $5 \% \mathrm{CO}_{2}$. Free parasites were removed by washing 2-3 times with serum-free RPMI medium. After $72 \mathrm{~h}$ at $37^{\circ} \mathrm{C}$ under $5 \% \mathrm{CO}_{2}$, trypomastigotes were collected from the culture supernatant, centrifuged at $600 \times g$ for $30 \mathrm{~min}$, and then left under the same conditions for $3 \mathrm{~h}$. The number of viable trypomastigotes was determined by counting in a Neubauer chamber, and viable trypomastigotes were used for further assays.

\section{Human THP-1-derived macrophages}

The human monocytic cell line THP-1 (ATCC TIB202), derived from an acute monocytic leukaemia, was cultured and differentiated into macrophages as previously described [19]. THP-1-derived macrophages (THP-1 $\mathrm{M} \phi$ ) were used to evaluate the gene expression profile in THP-1 M $\phi$ s infected with T. cruzi benznidazole-sensitive and naturally benznidazole-resistant strains and then treated with BZ.

\section{Trypanosoma cruzi infection and benznidazole treatment} THP-1 M $\phi$ cells were infected with T. cruzi trypomastigotes of the CL Brener clone and Colombiana strain, followed by a $14 \mathrm{~h}$ incubation $\left(5 \% \mathrm{CO}_{2}, 37{ }^{\circ} \mathrm{C}\right)$ to allow differentiation into intracellular amastigotes. Infected cells were treated for $48 \mathrm{~h}$ with $\mathrm{BZ}$ at concentrations ranging from 3 to $100 \mu \mathrm{M}$ to determine the $\mathrm{IC}_{50}$ for both strains by sigmoidal regression analysis (variable slope response) using GraphPad Prism 5 software (GraphPad Inc., San Diego, CA, USA). To evaluate the gene expression mRNA levels in the treated groups, $13 \mu \mathrm{M}$ BZ (the $\mathrm{IC}_{80}$ for the sensitive phenotype being equivalent to the $\mathrm{IC}_{60}$ for the resistant phenotype) was used to treat THP-1 $\mathrm{M} \phi$ cells. Controls (infection-free and drug-free macrophages) were included in all assays. Samples were collected and stored in TRIzol (Invitrogen, Sao Paulo, Brazil) 
for RNA extraction, PCR array and RT-qPCR assays. In parallel, identically infected and drug-treated cells seeded in chamber slides were evaluated to assess their level of infection. The number of amastigotes per cell (parasite load) was determined by randomly counting 300 cells per well through conventional microscopy under $100 \times$ magnification in Giemsa-stained preparations; the percentage of parasite survival and parasitic index were determined as previously described by Sereno et al. [20].

\section{RNA extraction and first-strand CDNA synthesis}

Total RNA was isolated with the RNeasy Mini Kit (Qiagen, Maryland, USA) following the manufacturer's instructions. Total RNA was quantified using a PicoDrop P200 spectrophotometer (PicoDrop Technologies, Hinxton, UK). First strand cDNA was synthesized with an $\mathrm{RT}^{2}$ First Strand kit (SABiosciences, Maryland, USA) in reaction volumes of $20 \mu \mathrm{l}$, using $70 \mathrm{ng}$ of total RNA as previously described [21]. The cDNA was diluted to $111 \mu \mathrm{l}$ by adding RNase-free water and stored at $-20{ }^{\circ} \mathrm{C}$ until further use.

\section{$\mathrm{RT}^{2}$ Profiler ${ }^{\mathrm{TM}} \mathrm{PCR}$ arrays of THP- $1 \mathrm{M} \varphi$ cells and PCR array data analysis}

cDNA was mixed with RT2 SYBR Green/ROX qPCR Mastermix (SABiosciences) to assess the gene expression level of 168 genes using the RT2 Profiler PCR Arrays kit, which includes 84 human drug transporter genes (catalogue number PAHS-070Z, SABiosciences) and 84 human oxidative stress genes (catalogue number PAHS065Z, SABiosciences), following the manufacturer's instructions. The arrays contain a panel of standard controls to monitor genomic DNA contamination as well as first-strand synthesis and real-time PCR efficiency. Data were analysed by the $\Delta \Delta \mathrm{Ct}$ method as described previously [21].

\section{RT-qPCR validation}

The arrays were validated by RT-qPCR using mRNA from the group described above. Three representative genes of the array (MT3, AQP1 and AQP7) were chosen based on their putative significance in drug detoxification and antioxidant defence involvement, and RT-qPCR was performed with the same sets of primers used in the gene array assays (SABiosciences).

\section{Statistical analyses}

Differences were examined by two-way analysis of variance (ANOVA) followed by Bonferroni post hoc tests, as described in the figure legends. Analyses were performed with GraphPad Prism 5, and $P$-values of $<0.05$ were considered significant.

\section{Results and discussion}

Effect of benznidazole on the intracellular

viability of benznidazole-sensitive and naturally

benznidazole-resistant $T$. cruzi strains in human THP-1 MФ

cells

The dose-response assays to assess the efficacy of the drug against intracellular amastigotes showed that the $\mathrm{IC}_{50}$ of $\mathrm{BZ}$ for the T. cruzi Colombiana strain was 2.82fold greater than that for the CL Brener strain (Table 1). As expected, the percentage of intracellular parasite survival was significantly greater for the naturally resistant strain (Colombiana; 73.7\%) in contrast to the sensitive CL Brener strain (26.7\%) after treatment with $13 \mu \mathrm{M}$ BZ (Fig. 1a). Differences in intracellular parasite survival for both T. cruzi strains after treatment with BZ in other host cell lines has also previously been reported [15, 22]. Although THP-1 MФ cells infected with the Colombiana strain showed a higher parasite load than those infected with CL Brener after treatment with $13 \mu \mathrm{M} \mathrm{BZ}$ (ANOVA: $\left.F_{(1,2)}=84.0, P=0.0117\right)$, no differences were observed for the number of amastigotes/cell in infected cells without treatment (Fig. 1b, c).

\section{Effect of benznidazole treatment on drug transporter and oxidative stress gene expression levels in human macrophages infected with benznidazole-sensitive and naturally benznidazole-resistant $T$. cruzi strains}

The determination of a possible association between parasite sensitivity phenotypes and their capacity to regulate human macrophage responses requires the use of naturally resistant pathogens to drugs [23]. We used the T. cruzi-macrophage-drug interaction model to address this assumption and to obtain global insights to understand the role of human responses to infection and drug treatment interaction by evaluating the gene expression profiles in human THP-1 MФ cells infected with CL Brener and Colombiana treated or not treated with BZ. Our results led to the identification of differentially regulated species-specific host genes and enabled us to identify potential markers associated with BZ resistance

Table 1 The effect of benznidazole treatment on intracellular amastigotes of sensitive (CL Brener) and resistant (Colombiana) Trypanosoma cruzi strains in THP-1 macrophages

\begin{tabular}{lll}
\hline T. cruzi strain & $\mathrm{IC}_{50}(95 \% \mathrm{Cl}) \mathrm{BZ}(\mu \mathrm{M})$ & $\begin{array}{l}\text { Resistance } \\
\text { index }\end{array}$ \\
\hline CL Brener & $3.2(2.47-4.12)$ & na \\
Colombiana & $9.01(5.67-14.32)$ & 2.82 \\
\hline
\end{tabular}

\footnotetext{
a Resistance index was calculated by the ratio of the $\mathrm{IC}_{50}$ value for the $T$. cruzi naturally benznidazole-resistant (Colombiana) and the sensitive (CL Brener) strains

Abbreviation: na, not applicable
} 


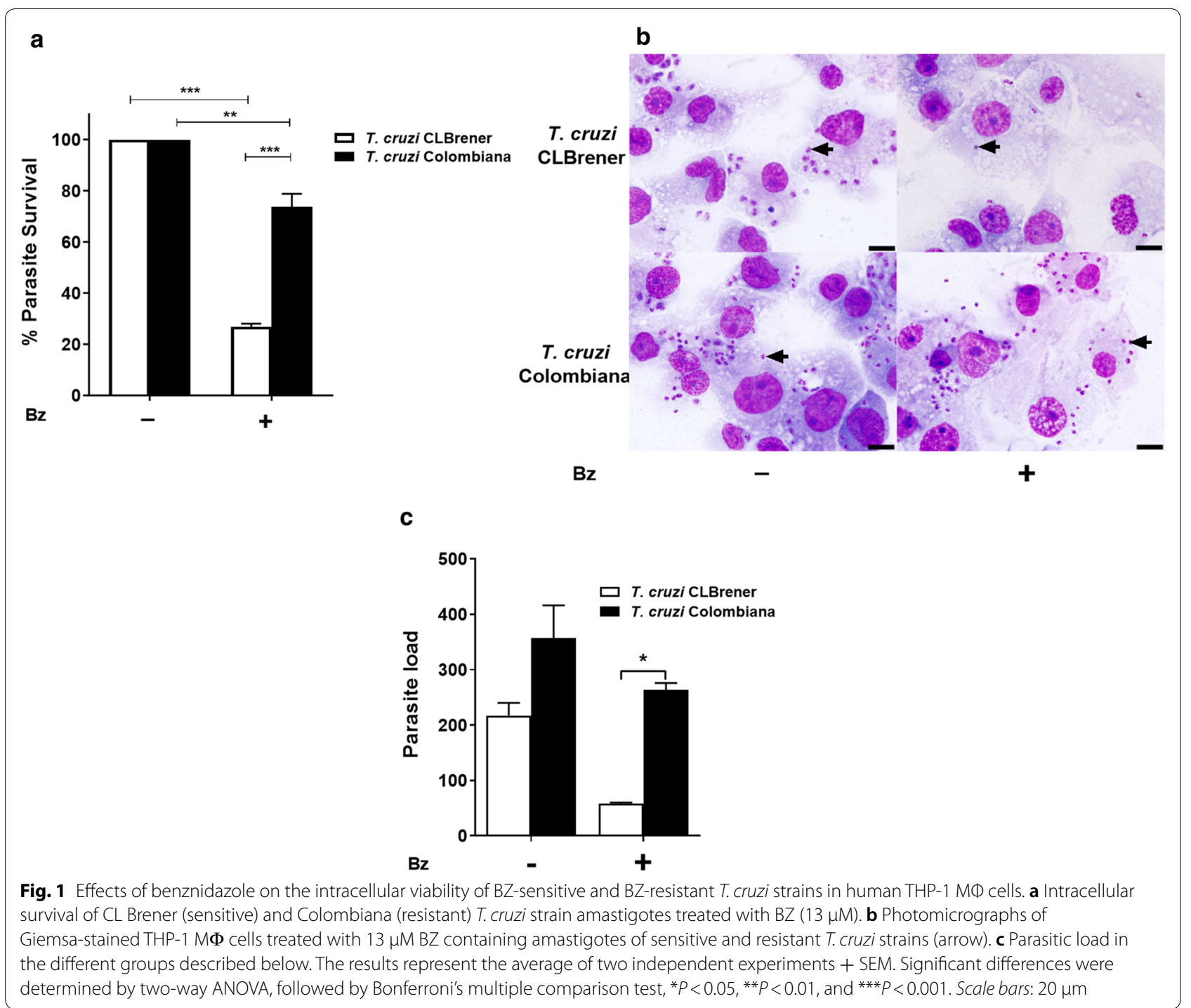

in human THP-1 macrophages infected with T. cruzi. A 3-fold difference in gene expression compared to the controls (THP-1 macrophages without infection and without treatment) was established as an arbitrary cut-off. Overall, the expression level of $62(36.9 \%)$ of the evaluated genes changed in the host by at least 3-fold upon infection with CL Brener and BZ treatment, with 27.4\% (46/168) of the genes being upregulated and $9.52 \%(16 / 168)$ of the genes being downregulated (Fig. 2a). In addition, the expression level of 32 (19.05\%) genes changed in THP-1 MФ cells infected with Colombiana and treated with BZ, with $17.3 \%(29 / 168)$ of the genes being upregulated and $1.79 \%(3 / 168)$ of the genes being downregulated (Fig. 2a). Of the 46 upregulated genes in THP-1 MФ cells infected with CL Brener and treated with BZ, 73.9\% and $26.1 \%$ belonged to the drug transporter and oxidative stress pathways, respectively (Fig. 2b, c). In contrast, all
29 genes upregulated in THP-1 MФ cells infected with Colombiana and treated with $\mathrm{BZ}$ belonged to the drug transporter group, and none belonged to the oxidative stress pathway (Fig. 2b).

In the T. cruzi-macrophage-BZ interaction model, we found changes in gene expression levels in pathways related to antioxidant defence, superoxide metabolism, oxidative stress response and solute drug transporters. Among the genes that were differentially expressed by infection and treatment, we focussed on the genes $A Q P 1, A Q P 7, A Q P 9$ and $A B C B 1$ (MDR1), which could be involved in BZ uptake and drug activity against intracellular amastigotes (Fig. 3, Additional file 1: Table S1, Additional file 2: Table S2). Interestingly, no association data between $A Q P$ or $A B C B 1$ modulation has been demonstrated in T. cruzi [24]. However, the involvement of these proteins in drug uptake 
a

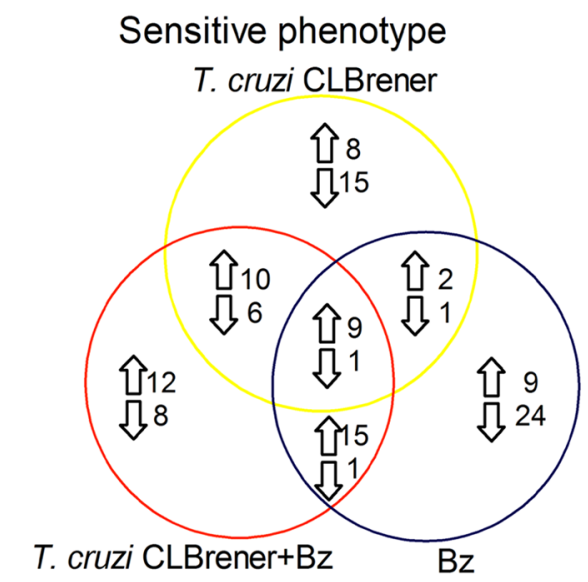

b

Sensitive phenotype T. cruzi CLBrener

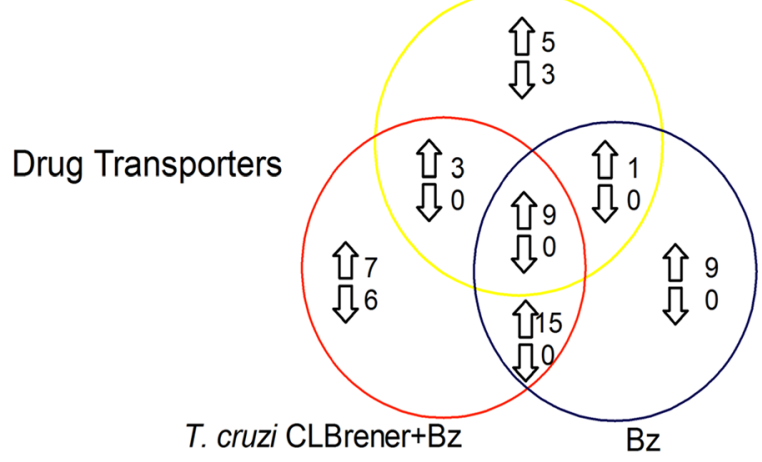

c

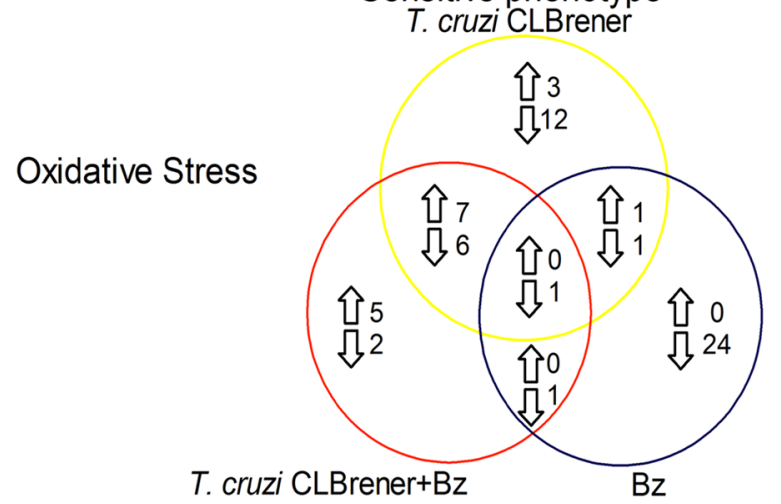

\section{Resistant phenotype}

T. cruzi Colombiana

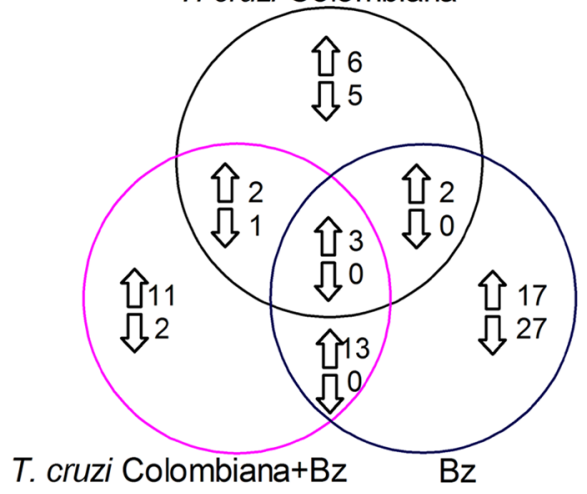

T. cruzi Colombiana+Bz
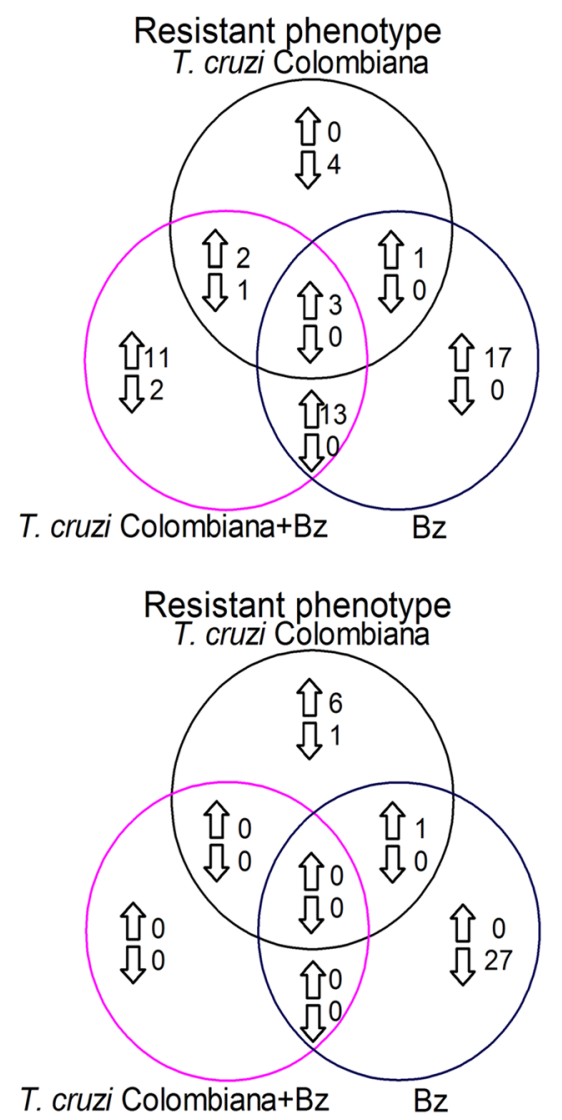

Fig. 2 Venn diagram showing the number of transcripts upregulated and downregulated in human THP-1 MФ cells. a Total number of commonly or differentially expressed gene transcripts in differentiated THP-1 macrophages. b Number of gene transcripts of the drug transporter pathway. $\mathbf{C}$ Number of gene transcripts of the oxidative stress pathway. THP-1 MФ cells infected with Trypanosoma cruzi CL Brener strain (yellow circles), THP-1 MФ cells treated with benznidazole (dark blue circles), THP-1 MФ cells infected with T. cruzi CL Brener strain and then treated with benznidazole (red circles), THP-1 MФ cells infected with T. cruzi Colombiana strain (black circles), or THP-1 MФ cells infected with T. cruzi Colombiana strain and then treated with benznidazole (pink circles). Upregulated genes are indicated by up arrows, and downregulated genes are indicated by down arrows in the different groups. The number of gene transcripts in the THP-1 MФ cells corresponds to the mean of three independent experiments 


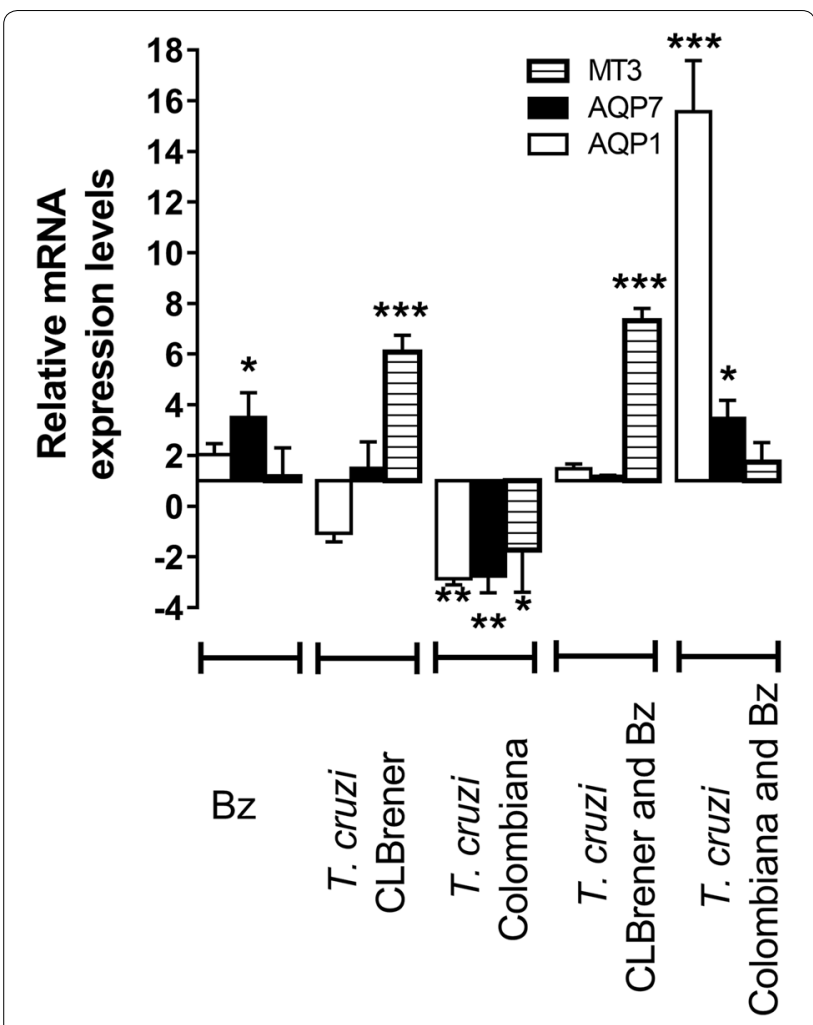

Fig. 3 RT-qPCR validation of transcript expression of drug transporters and oxidative stress arrays in BZ-sensitive and BZ-resistant T cruzi-infected THP-1 MФ cells treated with BZ. Relative mRNA expression is expressed as a ratio of transcripts in the study groups compared to transcripts in the control group (differentiated THP-1 macrophages without infection and without treatment). The values presented for the quantitative reverse-transcriptase real-time PCR analyses are the mean of the ratios of macrophage transcripts from two independent experiments. The gene expression in the study groups was normalized to GAPDH. The genes listed are MT3, metallothionein 3; $A Q P 1$, aquaporin 1; and $A Q P 7$, aquaporin 7. Significant differences were determined by two-way ANOVA, followed by Bonferroni's multiple comparison test, ${ }^{*} P<0.05$, ${ }^{*} P<0.01$, and ${ }^{* * *} P<0.001$

mechanisms by the host cell and the association with resistance phenotypes to $\mathrm{BZ}$ constitutes a broad field to be investigated. Furthermore, functional studies in other host cell response models have shown that the heterologous expression of the mammalian $A Q P 7$ and $A Q P 9$ genes allows for the absorption of AsIII and SbIII when expressed in S. cerevisiae or in Xenopus laevis oocytes [25]. Additionally, downregulation of the $A Q P 1$ gene, which is homologous to the mammalian $A Q P 9$ gene, has been reported to be associated with resistance phenotypes in Leishmania spp. [26, 27]. The regulation of human drug transporter and oxidative stress genes in response to $T$. cruzi infection and BZ treatment, regardless of the strain's phenotype, has not been described to date in human macrophages to the best of our knowledge. These findings suggest that genes associated with drug transporters could be involved in the toxic effects of BZ in host cells.

THP-1 cells infected with T. cruzi and THP-1 MФ cells treated with BZ showed a gene modulation profile that was different from that of infected and treated cells, particularly for genes involved in antioxidant defence (Additional file 2: Table S2). In the THP-1 $M \Phi$ cells infected with CL Brener, $17.3 \%$ of the genes $(29 / 168)$ were upregulated, and three of these genes were modulated exclusively in this group (Fig. 2a, Additional file 1: Table S1, Additional file 2: Table S2). In the THP-1 MФ cells infected with Colombiana, 13 upregulated genes were found, but none of these genes were exclusive to this group (Fig. 2a). In the THP-1 MФ cells not infected but treated with BZ, $20.8 \%$ of the genes (35/168 genes) were upregulated, with three of the genes being exclusive to the group (Fig. 2a, Additional file 1: Table S1, Additional file 2: Table S2). Among the 35 genes that were upregulated in the treated group, we highlighted the expression levels of $A B C C 2 / M R P 2$ [ATP-binding cassette, sub-family C (CFTR/MRP), member 2]. Despite the high mRNA expression levels of $M R P 2$ observed in all treated conditions, the results suggest that this transporter may play a role in BZ detoxification. MRP2 has been reported to be involved in xenobiotic efflux, which potentially induces oxidative stress in host cells [28]. Moreover, MRP2 extrudes GSSG, which, along with de novo GSH synthesis, contributes to the return of normal GSH levels and redox homeostasis [28].

In the THP-1 MФ cells infected with CL Brener, 13.7\% of the genes (23/168 genes) were downregulated, with 13 of the genes belonged exclusively to this group (Fig. 2a, Additional file 1: Table S1, Additional file 2: Table S2). Among these 13 genes, we observed the modulation of SOD1 (superoxide dismutase 1, soluble), SOD2 (superoxide dismutase 2, mitochondrial), $T X N$ (thioredoxin) and TXNRD1 (thioredoxin reductase 1), which are related to antioxidant defence, and this finding is consistent with the ability of macrophages to control infection. In the THP-1 MФ cells infected with Colombiana, six downregulated genes were found, one of which belonged solely to this group (Fig. 2a). Furthermore, it has been reported that the human response to T. cruzi infection has large differences that reflect the parasite's adaptation to distinct environments during the infection of mammalian cells, including changes in energy sources, oxidative stress responses, cell cycle control and cell surface components [29]. Taken together, our results suggest that $T$. cruzi could modulate particular genes for its own protection and replication in the intracellular host environment. 
In the THP-1 M $\Phi$ cells treated with BZ, $16.1 \%$ of genes (27/168 genes) were downregulated, with 14 genes belonging exclusively to this group (Fig. 2a, Additional file 1: Table S1, Additional file 2: Table S2). Among these genes, we identified CAT (catalase), GCLC (glutamatecysteine ligase catalytic subunit), GCLM (glutamatecysteine ligase modifier subunit), GPX1 (glutathione peroxidase 1), GSR (glutathione reductase), GSS (glutathione synthetase) and GSTP1 (glutathione S-transferase $\pi 1$ ) (Additional file 2: Table S2). In contrast to our findings of downregulation of these genes, recent studies have shown enzymatic upregulation of CAT, SOD and GPX as a natural response to attenuate damage mediated by ROS/RNS after $12 \mathrm{~h}$ of exposure to BZ [28, 30]. These differences suggest that to evaluate the significance of these results, a strategy combining different time points could elucidate the true involvement of these molecules in host cell responses to BZ treatment.

Similar to antimony compounds, the first-line drugs for leishmaniasis treatment, the mode of action of $\mathrm{BZ}$ remains unclear, and the participation of the host cell in these mechanisms has been virtually unexplored [31]. Recently, it has been reported that BZ activity in T. cruzi is associated with the intracellular formation of BZ conjugates with thiols, producing an endogenous depletion of these molecules in the parasite, further increasing its defence against oxidative stress and generated electrophilic metabolites $[6,32]$.

$\mathrm{BZ}$ has been found to induce the overexpression and increase the activity of biotransformation enzymes (also referred to as drug metabolizing enzymes), such as GSTP (glutathione S-transferase $\pi 1$ ), or drug transporters, such as P-gp and MRP2, in a dose-dependent manner in the HepG2 cell line [31]. Modulation of these enzymes was observed when cells were exposed to a concentration of $200 \mu \mathrm{M}$ BZ, but not at lower doses [31]. Recently, in $T$. cruzi, it has been reported that high levels of gene expression and activity of the $M D R 1$ efflux transporter induce parasite resistance to BZ [33]. In 2016, Perdomo et al. [13] reported that P-gp and MRP2 activities were correlated with increased protein levels, inducing lower BZ intracellular accumulation in THP-1 human macrophages. Functional data from the inhibition of the expression of GSTP enzymes by PXR (pregnane $X$ receptor) suggest that GSTP, P-gp and MRP2 are involved in BZ detoxification [31]. These results have subsequently been confirmed with in vivo studies in mice, where treatment with BZ increased the expression and activity of GSTP, P-gp and MRP2, mainly in the liver and in the proximal intestine [14]. The lack of GSTP1 modulation in the T. cruziBZ-macrophage interaction model is consistent with previous reports, probably due to the working dose of 13 $\mu \mathrm{M}$, which is consistent with the absence of modulation in low-dose exposure to BZ previously reported by Rigalli et al. [31]. To the best of our knowledge, no studies in the THP-1 human cell line have found an association between resistance phenotypes and drug sensitivity in intracellular T. cruzi strain interactions or described their effects on the modulation of gene expression in host cells after drug treatment. However, several studies have focused on parasite resistance to BZ, employing methods such as proteomics and metabolomics, or a host cell response to $T$. cruzi infection alone [29, 32, 34-39].

\section{Conclusions}

Our findings support the value of gene expression studies focused on the host response to pathogens and drug treatments integrated with functional and metabolic data to identify potentially novel targets for the treatment of this important and neglected tropical disease.

\section{Additional files}

Additional file 1: Table S1. Regulation of drug transporter gene expres sion levels in human THP-1 MФ cells by benznidazole (BZ) and T. cruzi infection.

Additional file 2: Table S2. Regulation of oxidative stress gene expression levels in human THP-1 MФ cells by benznidazole (BZ) and T. cruzi infection.

\section{Abbreviations}

NFX: nifurtimox; BZ: benznidazole; qPCR: quantitative polymerase chain reaction; RT-qPCR: real-time quantitative PCR; THP-1 MФ: human acute monocytic leukaemia cell line differentiated into macrophages.

\section{Acknowledgements}

Not applicable.

\section{Funding}

JT and IR were recipients of Coordenação de Aperfeiçoamento de Pessoal de Nível Superior (CAPES) scholarships. CAPES and Conselho Nacional de Desenvolvimento Científico e Tecnológico (CNPq)-Brazilian Government Agencies (grant 475474/2011-2) supported this work. The funders played no role in the study design, data generation and analysis, decision to publish, or preparation of the manuscript.

\section{Availability of data and materials}

All data generated or analysed during the present study are included in this published article and its additional files.

\section{Authors' contributions}

JT: conceptualization, data acquisition, data curation, formal analysis, funding acquisition, investigation methodology, project administration, supervision, validation, visualization, writing of the original draft. IB: conceptualization, data acquisition, data curation, formal analysis, investigation methodology, validation, writing of the original draft. AR: funding acquisition, supervision, validation, reviewing and editing of the original draft. MS: conceptualization, data curation, formal analysis, funding acquisition, resources, supervision, validation, reviewing and editing of the original draft. All authors read and approved the final manuscript.

Ethics approval and consent to participate Not applicable. 


\section{Consent for publication \\ Not applicable.}

\section{Competing interests}

The authors declare that they have no competing interests.

\begin{abstract}
Author details
${ }^{1}$ Laboratorio de Protozoologia, Departamento de Microbiologia, Imunologia e Parasitologia, Centro de Ciências Biológicas, Universidade Federal de Santa Catarina, Florianópolis, SC, Brazil. ${ }^{2}$ Vicerrectoría de Investigaciones, Universidad Manuela Beltrán, Bogotá, Cundinamarca, Colombia. ${ }^{3}$ Programa de Ciencias Básicas, Universidad Manuela Beltrán, Bogotá, Cundinamarca, Colombia.
\end{abstract}

Received: 20 November 2018 Accepted: 6 May 2019

Published online: 24 May 2019

\section{References}

1. Molina I, Salvador F, Sánchez-Montalvá A, Artaza MA, Moreno R, Perin $L$, et al. Pharmacokinetics of benznidazole in healthy volunteers and implications in future clinical trials. Antimicrob Agents Chemother. 2017;61:e01912-6.

2. Altcheh J, Moscatelli G, Mastrantonio G, Moroni S, Giglio N, Marson ME, et al. Population pharmacokinetic study of benznidazole in pediatric Chagas disease suggests efficacy despite lower plasma concentrations than in adults. PLoS Negl Trop Dis. 2014;8:e2907.

3. Novaes RD, Santos EC, Cupertino MC, Bastos DSS, Oliveira JM, Carvalho TV, et al. Trypanosoma cruzi infection and benznidazole therapy independently stimulate oxidative status and structural pathological remodeling of the liver tissue in mice. Parasitol Res. 2015;114:2873-81.

4. Rassi AJ, Rassi A, Marin-Neto JA. Chagas disease. Lancet. 2010;375:1388-402

5. Urbina JA. Specific chemotherapy of Chagas disease: relevance, current limitations and new approaches. Acta Trop. 2010;115:55-68.

6. Maya JD, Cassels BK, Iturriaga-Vásquez P, Ferreira J, Faúndez M, Galanti N, et al. Mode of action of natural and synthetic drugs against Trypanosoma cruzi and their interaction with the mammalian host. Comp Biochem Physiol A Mol Integr Physiol. 2007;146:601-20.

7. Wilkinson SR, Bot C, Kelly JM, Hall BS. Trypanocidal activity of nitroaromatic prodrugs: current treatments and future perspectives. Curr Top Med Chem. 2011;11:2072-84.

8. Hall BS, Wilkinson SR. Activation of benznidazole by trypanosomal type I nitroreductases results in glyoxal formation. Antimicrob Agents Chemother. 2012;56:115-23.

9. Wilkinson SR, Taylor MC, Horn D, Kelly JM, Cheeseman I. A mechanism for cross-resistance to nifurtimox and benznidazole in trypanosomes. Proc Natl Acad Sci USA. 2008;105:5022-7.

10. Bulffer RF, Castro JA, Fanelli SL. Benznidazole levels in blood vary with age in rats. Mem Inst Oswaldo Cruz. 2011;106:374-7.

11. Castro JA, deMecca MM, Bartel LC. Toxic side effects of drugs used to treat Chagas' disease (American trypanosomiasis). Hum Exp Toxicol. 2006:25:471-9.

12. Maya JD, Orellana M, Ferreira J, Kemmerling U, López-Muñoz R, Morello A. Chagas disease: present status of pathogenic mechanisms and chemotherapy. Biol Res. 2010;43:323-31.

13. Perdomo VG, Rigalli JP, Luquita MG, Pellegrino JM, Ruiz ML, Catania VA, et al. Up-regulation of ATP-binding cassette transporters in the THP-1 human macrophage cell line by the antichagasic benznidazole. Mem Inst Oswaldo Cruz. 2016;111:707-11.

14. Perdomo VG, Rigalli JP, Villanueva SSM, Ruiz ML, Luquita MG, Echenique $C G$, et al. Modulation of biotransformation systems and $A B C$ transporters by benznidazole in rats. Antimicrob Agents Chemother. 2013;57:4894-902.

15. Filardi LS, Brener Z. Susceptibility and natural resistance of Trypanosoma cruzi strains to drugs used clinically in Chagas disease. Trans R Soc Trop Med Hyg. 1987;81:755-9.

16. Mejía-Jaramillo AM, Fernández GJ, Montilla M, Nicholls RS, Triana-Chávez O. Trypanosoma cruzi strains resistant to benznidazole occurring in Colombia. Biomedica. 2012;32:196-205.
17. Murta SMF, Gazzinelli RT, Brener Z, Romanha AJ. Molecular characterization of susceptible and naturally resistant strains of Trypanosoma cruzi to benznidazole and nifurtimox. Mol Biochem Parasitol. 1998;93:203-14.

18. Romero I, Téllez J, Yamanaka LE, Steindel M, Romanha AJ, Grisard EC. Transsulfuration is an active pathway for cysteine biosynthesis in Trypanosoma rangeli. Parasit Vectors. 2014;7:197.

19. Romero I, Téllez J, Romanha AJ, Steindel M, Grisard EC. Upregulation of cysteine synthase and cystathionine $\beta$-synthase contributes to Leishmania braziliensis survival under oxidative stress. Antimicrob Agents Chemother. 2015;59:4770-81.

20. Sereno D, Holzmuller P, Lemesre JL. Efficacy of second line drugs on antimonyl-resistant amastigotes of Leishmania infantum. Acta Trop. 2000;74:25-31.

21. Téllez J, Romero I, Soares MJ, Steindel M, Romanha AJ. Knockdown of host antioxidant defense genes enhances the effect of glucantime on intracellular Leishmania braziliensis in human macrophages. Antimicrob Agents Chemother. 2017;61:e02099

22. Luna KP, Hernández IP, Rueda CM, Zorro MM, Croft SL, Escobar P. In vitro susceptibility of Trypanosoma cruzi strains from Santander, Colombia, to hexadecylphosphocholine (miltefosine), nifurtimox and benznidazole. Biomédica. 2009;29:448-55

23. Sundar S, Goyal N. Molecular mechanisms of antimony resistance in Leishmania. J Med Microbiol. 2007;56:143-53.

24. Mandal G, Orta JF, Sharma M, Mukhopadhyay R. Trypanosomatid aquaporins: roles in physiology and drug response. Diseases. 2014;2:3-23.

25. Liu Z, Shen J, Carbrey JM, Mukhopadhyay R, Agre P, Rosen BP. Arsenite transport by mammalian aquaglyceroporins AQP7 and AQP9. Proc Natl Acad Sci USA. 2002;99:6053-8.

26. Marquis N, Gourbal B, Rosen BP, Mukhopadhyay R, Ouellette M. Modulation in aquaglyceroporin AQP1 gene transcript levels in drug-resistant Leishmania. Mol Microbiol. 2005:57:1690-9.

27. Gourbal B, Sonuc N, Bhattacharjee H, Legare D, Sundar S, Ouellette M, et al. Drug uptake and modulation of drug resistance in Leishmania by an aquaglyceroporin. J Biol Chem. 2004;279:31010-7.

28. Rigalli JP, Perdomo VG, Ciriaci N, Francés DEA, Ronco MT, Bataille AM, et al. The trypanocidal benznidazole promotes adaptive response to oxidative injury: involvement of the nuclear factor-erythroid 2-related factor-2 (Nrf2) and multidrug resistance associated protein 2 (MRP2). Toxicol Appl Pharmacol. 2016;304:90-8.

29. Belew AT, Junqueira C, Rodrigues-Luiz GF, Valente BM, Oliveira AER, Polidoro RB, et al. Comparative transcriptome profiling of virulent and non-virulent Trypanosoma cruzi underlines the role of surface proteins during infection. PLoS Pathog. 2017;13:e1006767.

30. Santos EC, Novaes RD, Bastos DSS, Oliveira JM, Penitente AR, Gonçalves WG, et al. Modulation of oxidative and inflammatory cardiac response by nonselective 1- and 2-cyclooxygenase inhibitor and benznidazole in mice. J Pharm Pharmacol. 2015;67:1556-66.

31. Rigalli JP, Perdomo VG, Luquita MG, Villanueva SSM, Arias A, Theile D, et al. Regulation of biotransformation systems and $A B C$ transporters by benznidazole in HepG2 cells: involvement of pregnane X-receptor. PLoS Negl Trop Dis. 2012;6:e1951.

32. Trochine A, Creek DJ, Faral-Tello P, Barrett MP, Robello C. Benznidazole biotransformation and multiple targets in Trypanosoma cruzi revealed by metabolomics. PLoS Negl Trop Dis. 2014;8:e2844.

33. Campos MCO, Castro-Pinto DB, Ribeiro GA, Berredo-Pinho MM, Gomes LHF, da Silva Bellieny MS, et al. P-glycoprotein efflux pump plays an important role in Trypanosoma cruzi drug resistance. Parasitol Res. 2013;112:2341-51.

34. Villarreal $D$, Nirdé $P$, Hide M, Barnabé $C$, Tibayrenc M. Differential gene expression in benznidazole-resistant Trypanosoma cruzi parasites. Antimicrob Agents Chemother. 2005;49:2701-9.

35. Andrade HM, Murta SMF, Chapeaurouge A, Perales J, Nirdé P, Romanha AJ. Proteomic analysis of Trypanosoma cruzi resistance to benznidazole. J Proteome Res. 2008:7:2357-67.

36. dos Santos PF, Ruiz JC, Soares RPP, Moreira DS, Rezende AM, Folador $E L$, et al. Molecular characterization of the hexose transporter gene in benznidazole resistant and susceptible populations of Trypanosoma cruzi. Parasit Vectors. 2012;5:161.

37. Li Y, Shah-Simpson S, Okrah K, Belew AT, Choi J, Caradonna KL, et al. Transcriptome remodeling in Trypanosoma cruzi and human cells during intracellular infection. PLoS Pathog. 2016;12:e1005511. 
38. Chiribao ML, Libisch G, Parodi-Talice A, Robello C. Early Trypanosoma cruzi infection reprograms human epithelial cells. Biomed Res Int. 2014;2014:439501.

39. Castillo C, Carrillo I, Libisch G, Juiz N, Schijman A, Robello C, et al. Hostparasite interaction: changes in human placental gene expression induced by Trypanosoma cruzi. Parasit Vectors. 2018;11:479.

\section{Publisher's Note}

Springer Nature remains neutral with regard to jurisdictional claims in published maps and institutional affiliations.
Ready to submit your research? Choose BMC and benefit from:

- fast, convenient online submission

- thorough peer review by experienced researchers in your field

- rapid publication on acceptance

- support for research data, including large and complex data types

- gold Open Access which fosters wider collaboration and increased citations

- maximum visibility for your research: over 100M website views per year

At BMC, research is always in progress.

Learn more biomedcentral.com/submissions 